\title{
La violación al principio de planeación contractual como causal de anulabilidad absoluta del contrato estatal
}

\author{
Violation of the principle of contractual planning as grounds for absolute voidability \\ of the state contract
}

\section{${ }^{*}$ Luis Carlos Alzate Ríos}

* Abogado, especialista en Derecho Público, Derecho Comercial, Derecho Administrativo, Derecho Tributario y Contratación Estatal. Magíster en Derecho Procesal y en Tributación Internacional, Aduanas y Comercio Exterior. Profesor universitario e investigador en pregrado y posgrado en las áreas del derecho público, en la Universidad La Gran Colombia.

Fecha de recepción: Noviembre de 2019 Fecha de aprobación: marzo de 2020

Para citar este artículo / To reference this article La violación al principio de planeación contractual como causal de anulabilidad absoluta del contrato estatal. Inciso, 22(1) ;

DOI: http://dx.doi.org/10.18634/incj.22v.1i.1030

\section{Resumen}

Se presenta el alcance del principio de planeación en la contratación estatal y si este al ser transgredido genera la anulabilidad del contrato estatal. Para responder a dicha inquietud, se desarrolla desde el punto de vista constitucional, legal, reglamentario, doctrinal y jurisprudencial el contenido del principio en estudio y se elabora la línea jurisprudencial sobre si la violación al mismo es causal de nulidad absoluta del contrato estatal, derivando del estudio realizado la importancia del principio bajo análisis a tal punto que se concluye que su desconocimiento si genera la nulidad absoluta, bajo condición de que se imposibilite la ejecución adecuada del contrato, ya sea desde los aspectos técnicos, jurídicos o financieros.

Palabras clave: contratación estatal, nulidad absoluta, principio de planeación. 


\section{Abstract}

The scope of the planning principle in state contracting is presented and if this, when violated, generates the annulment of the state contract. To answer this concern, the content of the principle under study is developed from the constitutional, legal, regulatory, doctrinal and jurisprudential point of view and the jurisprudential line is drawn up on whether the violation thereof is the cause of absolute nullity of the state contract, deriving of the study carried out the importance of the principle under analysis to such an extent that it is concluded that its ignorance does generate absolute nullity, under the condition that the proper execution of the contract is prevented, either from the technical, legal or financial aspects.

Keywords: state contracting, absolute nullity, planning principle.

\section{Introducción}

La contratación estatal en cualquier Estado social de derecho, como Colombia, resulta ser un tema de gran trascendencia desde el punto de vista jurídico, pues ella es una de las formas como la administración pública cumple sus fines en búsqueda de materializar el bienestar general y la prosperidad social. Es este uno de los aspectos por lo que se justifica que la contratación del Estado no se rija en su totalidad por las mismas normas que gobiernan la contratación privada.

Partiendo de dicha concepción y de las diferentes fuentes formales del derecho (en primer lugar, las normas constitucionales, legales y reglamentarias; en segundo lugar, la jurisprudencia con su valor de fuente de obligatoriedad relativa) se infiere un principio que rige la contratación estatal como lo es el de planeación, que conlleva a que la administración pública cuando emprende la adjudicación, suscripción y ejecución de un contrato estatal, previamente haya llenado una serie de requisitos que conforme a la ley, el reglamento y las previsiones que tendría un buen administrador de la Rēs pūblica, que no son otra cosa que la identificación de necesidades a cubrir, la meta que se persigue obtener, el servicio que se pretende satisfacer, etc., y la forma concreta todo esto se documentará en el contrato y se materializará en la ejecución del mismo; todo con el fin de satisfacer las necesidades colectivas que representa el Estado.

De allí pues que el estudio del principio de planeación sea uno de los objetivos que se pretende abordar, pues en su condición de principio, su alcance e interpretación debe ser fijado por el intérprete haciendo uso de las herramientas y mecanismos existentes para ello.

Por otro lado, para que el desarrollo del tema no se quede en el plano teórico, es menester que se estudie el principio de planeación en movimiento, por ello, se plantea el interrogante de si su violación llega a afectar la validez del contrato, a tal punto de lo anule.

Para el cumplimiento del anterior objetivo, se estudiaran, interpretaran y fijara el alcance de las normas que regulan el tema, la jurisprudencia (se resalta, con decisiones encontradas frente al tema), elaborando para ello la correspondiente línea jurisprudencial, una vez recolectada y analizada toda esta información se dará respuesta, con fundamento en la argumentación, a la pregunta que buscamos responder, que no es otra que si ¿La transgresión del principio de planeación contractual por parte del ente público contratante puede enmarcarse dentro de una de las causales de nulidad absoluta del contrato estatal? 
Como se planteó, en la estructura contemporánea de los sistemas normativos las disposiciones que contienen los mandatos obligatorios no poseen, en muchas oportunidades, la claridad deseada. Ello por la existencia misma de una distinción ya clásica al interior de las normas entre las que se denominan reglas y principios ${ }^{1}$ y de ella se han generado múltiples cambios en la teoría del derecho, en la aplicación del derecho, en la relación del derecho y la moral, y en la dogmática jurídica en general.

Una de las características más importante de los principios es que su contenido no es fijado de forma directa por la norma, sino que dependerá su alcance de las condiciones jurídicas y fácticas del caso, dando gran importancia al interprete para fijar su alcance de forma argumentada y racional, conforme al principio de proporcionalidad ${ }^{2}$, lo que a su vez soporta en gran parte la importancia que en la actualidad posee el precedente jurisprudencial de las altas $\operatorname{cortes}^{3}$ en ejercicio de sus competencias constitucionales y legales.

Partiendo entonces de lo anterior, es importante estudiar el verdadero alcance y contenido del principio de planeación al interior de la contratación estatal, a fin de fijar su relevancia y las consecuencias que genera su transgresión.

Por otro lado, como ya se advirtió, no existe uniformidad en las decisiones del máximo órgano de la jurisdicción de lo contencioso administrativo, el Consejo de Estado, en torno a la interpretación de si la transgresión del principio de planeación es causal o no de nulidad absoluta del contrato estatal. Este aspecto es de vital importancia, dado que fija las responsabilidades que poseen al interior de la relación sinalagmática como son los contratos, de las partes del mismo (por regla general contratante entidad estatal y contratista privado) que las más de las veces contraen obligaciones de contenido reciproco.

Para el desarrollo del tema, previamente se compilaron las normas aplicables en torno al principio de planeación contractual y las causales de anulabilidad del contrato estatal, frente al primero desde el punto de vista constitucional, legal y reglamentario, y frente al segundo desde el punto de vista constitucional y legal; atendiendo que estas son dos de las variables contenidas en el problema planteado, y se trata de relacionarlas en torno a la pregunta formulada.

Posteriormente, se realizó un rastreo bibliográfico frente a las dos variables ya identificadas contenidas en el problema (se reitera, el principio de planeación y las causales de anulabilidad absoluta del contrato estatal) procurando buscar y analizar las fuentes más recientes y actualizadas.

Una vez hecho lo anterior, se desarrollará el tema, en los dos primeros acápites (El principio de planeación contractual en la legislación vigente, la doctrina y la jurisprudencia; y causales de anulabilidad absoluta del contrato estatal) elaborando las conclusiones parciales de lo estudiado.

Posteriormente, se realizó un rastreo jurisprudencial sobre el problema de investigación que a su vez fue el problema jurídico de la línea jurisprudencial planteada, se realizó el análisis estático de las sentencias encontradas y posteriormente el análisis dinámico. Por último, se elaboran las conclusiones razonadas del tema presentado y de la pregunta formulada.

\footnotetext{
1. Entre quienes plantean dicha diferenciación, diferentes al autor analizado se encuentran: Dworkin. R. (2000). Los derechos en serio, Barcelona, Madrid: Ariel; Borowski, M. (2003). La estructura de los derechos fundamentales, Bogotá: Universidad Externado de Colombia; Zagrebelsky, G. (1999). El Derecho Dúctil. Madrid: Trotta; Valencia, H. (1999) Nomoárquica Principalistica Jurídica o de los Principios Generales del Derecho. Bogotá: Temis y Estrada, S. I. (2000) La excepción de principialidad, Bogotá: Temis; entre otros. 2 -Subprincipio de idoneidad

Una medida es idónea en su adopción si su adopción conduce a que se alcance o se favorezca la obtención del fin legítimo perseguido por le Estado. Un fin es legitimo si esta ordenado o en todo caso permitido constitucionalmente. Los fines ilegítimos son sólo aquellos cuya obtención está prohibida en la constitución.

-Subprincipio de necesidad

Una medida estatal no es necesaria si su finalidad también puede ser alcanzada por otro medio igualmente eficaz y que la vez no restrinja el derecho fundamental afectado o lo restrinja con una intensidad menor. Debe aclararse que no podrán considerarse como medios alternativos, todos aquellos que cumplan los presupuestos en esta definición, pero que a la vez afecten otras posiciones constitucionales.

- Subprincipio de proporcionalidad en sentido estricto

El principio de proporcionalidad en sentido estricto exige llevar a cabo una ponderación de bienes entre la gravedad o la intensidad de la intervención en el derecho fundamental, por una parte, y, por otra, el peso de las razones que la justifican. (Borowski, 2003, p. 130).

3. Importante aclara que en el sistema constitucional colombiano, entendemos por Altas Cortes la Corte Constitucional, la Corte Suprema de Justicia y el Consejo de Estado.
} 


\section{El principio de planeación contractual}

Como se plantea en la introducción, resulta indiscutible que la contratación estatal posee unas características especiales que la diferencian de la contratación entre privados, regida en su totalidad por las normas del derecho civil y comercial, las que no pueden desecharse de plano en la contratación estatal pues el mismo estatuto general remite a ellas (artículos 13 y 44 de la Ley 80 de 1993) los principios, fines y posición que posee el Estado en general y la administración en particular, es lo que ha determinado y justificado en países como el nuestro la existencia de una rama especializada del derecho, el derecho administrativo, y de una jurisdicción también especializada diferente a la ordinaria, la de lo contencioso administrativo, por lo que la interpretación y juzgamiento de los temas relacionados con el contrato estatal poseen una serie de premisas que lo diferencian de los de la contratación del derecho común, aspecto este que justifica una percepción diferente del objeto de estudio.

Para abordar el tema puesto a consideración, es menester que se parta de la base de los conceptos generales de contratación estatal, principios de la contratación estatal y dentro de ellos el de planeación del contrato y las causales generales de invalidación de los contratos, para luego relacionarlos y plantear de forma clara cuál es el problema concreto a resolver en torno al tema a investigar.

La contratación estatal es una de las formas como la administración pública materializa su actuar (al lado de los actos administrativos, lo hechos administrativos, las omisiones administrativas y las operaciones administrativas) como función estatal, satisface y cumple sus cometidos, en aras de buscar y materializar el interés general y el cumplimiento de los objetivos concretos para los que la correspondiente entidad u órgano que contrata.

Como marco de acción jurídica de la contratación de la administración pública tenemos, en términos generales, la Constitución Política, las leyes 80 de 1993 y 1150 de 2007, y el Decreto 1082 de 2015, dentro de ellas en este momento se resalta las siguientes que consagran los principios generales de la función administrativa en términos generales y la contratación estatal en particular:

- Artículo 209 de la Constitución Política que enlista los principios de la función administrativa los de igualdad, moralidad, eficacia, economía, celeridad, imparcialidad y publicidad.

- Artículos 339 y 341 de la Constitución Política, que enmarca la acción de Estado colombiano en un Plan Nacional de Desarrollo, que incluye una parte general y un Plan Nacional de Inversiones. Esta normativa también impone a los gobiernos territoriales a elaborar un Plan de Desarrollo, en coordinación con el gobierno nacional. De esta norma se infiere claramente que la planeación es un pilar fundamental de la administración del Estado colombiano tanto a nivel nacional como regional y local, siendo el Plan Nacional el faro de navegación de la administración pública.

- Artículo 3 de la Ley 489 de 1998 que enlista como principios de la función administrativa los de buena fe, igualdad, moralidad, celeridad, economía, imparcialidad, eficacia, eficiencia, participación, publicidad, responsabilidad y trasparencia.

- Los artículos 23, 24, 25 y 26 de la Ley 80 de 1993 que regulan los principios de transparencia, economía y responsabilidad.

- El artículo 3 de la Ley 1437 de 2001 que regula y enlista los principios de la actuación administrativa como son los del debido proceso, igualdad, imparcialidad, buena fe, moralidad, participación, responsabilidad, transparencia, publicidad, coordinación, eficacia, economía y celeridad. 
En este aspecto, es importante llamar la atención que estas normas dentro de la clasificación de las mismas, poseen estructura de principios, es decir, normas textura abierta que se caracterizan por solamente presentar una idea o postulado general, sin contener en ella supuesto de hecho y consecuencia jurídica como las reglas ${ }^{4}$.

Como se puede observar, en las fuentes formales principales del derecho, ya citadas (las de contenido normativo o legal, artículo 230 de la C.P.) la planeación no está consagrada de forma expresa como principio de la contratación estatal.

No obstante, lo anterior, dentro de la estructura del proceso de contratación estatal, que es esencialmente reglado, tenemos la etapa precontractual que se caracteriza por ser la de la planeación contractual (sección 2, subsección 1 planeación, artículos 2.2.1.1.2.1.1. a 2.2.1.1.2.1.5. del Decreto 1082 de 2015) y de ella dependerá en gran medida que el contrato cumpla con su fin, objeto adecuado y no sufra impases en su ejecución.

Como se dijo de forma expresa y se deduce de las normas legales ya citadas, si bien la planeación no está consagrada de forma expresa como principio de la contratación estatal, ella se deduce de los principios de eficacia ${ }^{5}$, eficiencia ${ }^{6}$ y economía ${ }^{7}$, pues de estos principios se infiere que la entidad debe realizar la correspondiente planeación del contrato que pretende suscribir a fin de satisfacer los fines de la contratación estatal que no son otros que los fines del Estado (artículos 3 de la Ley 80 de 1993 y 2 de la C.P.).

Así pues, de todas las anteriores normas se ha deducido la planeación como un principio esencial de la contratación estatal.

Sobre los principios mencionados y su vinculación necesaria con la planeación estatal como deber general del Estado, nos ilustra el Consejo de Estado:

La eficacia de todos los principios que rigen la actividad contractual del Estado, en especial los dos últimamente mencionados es decir el de la transparencia y el de la economía, depende en buena medida de que en ella se cumpla con los deberes de planeación y de selección objetiva.

Por supuesto que el cumplimiento de los demás deberes que la Constitución y la ley imponen en esa materia también aseguran la eficacia de todos los principios que la rigen y por ende la efectiva satisfacción del interés general que es lo que persigue la prestación de los servicios públicos mediante la actividad contractual del Estado.

De otro lado, el cumplimiento del deber de planeación permite hacer efectivo el principio de economía, previsto en la Carta y en el artículo 25 de la Ley 80 de 1993, porque precisando la oportunidad y por ende teniendo la entidad estatal un conocimiento real de los precios de las cosas, obras o servicios que constituyen el objeto del contrato, podrá no solamente aprovechar eficientemente los recursos públicos sino que también podrá cumplir con otro deber imperativo como es el de la selección objetiva pues tiene

4. Robert Alexy plantea, por una parte, el concepto de norma como genérico y, la regla y el principio como especies de normas, todas ellas como expresiones deónticas que manifiestan el deber ser (Mandato, permisión y prohibición). Dentro del estudio de dicha clasificación, se encuentran dos posiciones para fijar la diferencia existente entre reglas y principios; una de ellas basada en la idea de los principios y la optimización, es decir, plantea la existencia de principios que se caracterizan por ser mandatos de optimización, llamada la Teoría de los principios, que preona la existencia de los principios, plantean varios criterios para la diferenciación. Uno de los criterios es el de la generalidad, es decir, se basan en el aspecto cuantitativo de la norma para plantear su diferenciación. Así, si la norma consagra premisas generales y abstractas es un principio y si consagra premisas particulares y concretas es una regla. (Alzate, 2007, p. 69).

5. 1. f. Capacidad de lograr el efecto que se desea o se espera. Ver: www.rae.es

6. 1. f. Capacidad de disponer de alguien o de algo para conseguir un efecto determinado. Ver: www.rae.es

7 ... porque precisando la oportunidad y por ende teniendo la entidad estatal un conocimiento real de los precios de las cosas, obras o servicios que constituyen el objeto del contrato..." Consejo de Estado. Sala de lo Contencioso Administrativo. Sección Tercera. Subsección C. Consejero Ponente: Jaime Orlando Santofimio Gamboa. Sentencia del 24 de abril de 2013. Radicación número: 68001-23-15-000-1998-01743-01(27315). Actor: Jairo Ospina Cano. Demandado: Área Metropolitana De Bucaramanga. Referencia: Acción De Controversias Contractuales (Apelación Sentencia). 
la obligación de escoger la propuesta más favorable y la escogencia de esta también depende en últimas, como ya se vio, de la observancia del principio de planeación. (Consejo de Estado, 2013).

Así pues, desarrollemos el principio de planeación conforme lo consagran las normas citadas.

\section{Contenido legal del principio de planeación}

El principio de planeación aparece en la contratación estatal en todas las etapas del procedimiento contractual (pre, contractual y pos contractual) siendo la principal etapa en donde se materializa el mismo la precontractual, pues ella será la base de la futura contratación y servirá de fundamento para su ejecución.

Dentro de la Ley 80 de 1993, encontramos dos normas de donde se deduce el principio de planeación contractual, como son:

- El artículo 25 numerales 6, 7 y 11 a 14 de la Ley 80 de 1993, norma que consagra el principio de economía, y dentro de este establece:

- El deber de iniciar el proceso de suscripción del contrato, solo cuando existan las respectivas. partidas o disponibilidades presupuestales.

- La existencia de estudios de conveniencia o inconveniencia del objeto a contratar y las autorizaciones y aprobaciones para ello, previo al inicio del proceso de selección o firma de contrato.

- El deber de poseer los estudios, diseños y proyectos requeridos, previo a la apertura de un proceso de selección, o a la firma del contrato en el caso en que la modalidad de sele

- En los contratos de obra, previo a la apertura de un proceso de selección, la entidad contratante deberá contar con los estudios y diseños que permitan establecer la viabilidad del proyecto y su impacto social, económico y ambiental.

- La planeación incluye la constitución de las reservas y compromisos presupuestales necesarios, tomando como base el valor de las prestaciones al momento de celebrar el contrato y el estimativo de los ajustes resultantes de la aplicación de la cláusula de actualización de precios.

- El deber de incluir en sus presupuestos anuales una apropiación global destinada a cubrir los costos imprevistos ocasionados por los retardos en los pagos, así como los que se originen en la revisión de los precios pactados por razón de los cambios o alteraciones en las condiciones iniciales de los contratos por ellas celebrados.

El artículo 26 numeral 3 de la Ley 80 de 1993, norma que consagra el principio de responsabilidad, dentro de este establece:

- La responsabilidad de las entidades y los servidores públicos por abrir licitaciones sin haber elaborado previamente los correspondientes pliegos de condiciones, diseños, estudios, planos y evaluaciones que fueren necesarios, o cuando los pliegos de condiciones hayan sido elaborados en forma incompleta, ambigua o confusa que conduzcan a interpretaciones o decisiones de carácter subjetivo por parte de aquellos. 
Dentro de los contenidos normativos de orden legal, se destaca como fundamento de la planeación contractual el artículo 74 de la Ley 1474 de $2011^{8}$, como norma que consagra no solo el principio de publicidad, sino la planeación de la actividad contractual de la administración que incluye los proyectos, las metas, los responsables, los planes generales de compras y la distribución presupuestal de sus proyectos de inversión.

\section{Contenido reglamentario del principio de planeación:}

La norma reglamentaria (Decreto 1082 de 2015) desde las mismas definiciones (artículo 2.2.1.1.1.3.1.) se concentra en el desarrollo del principio de planeación, así:

Plan Anual de Adquisiciones: Plan general de compras al que se refiere el artículo 74 de la Ley 1474 de 2011 y el plan de compras al que se refiere la Ley Anual de Presupuesto. Es un instrumento de planeación contractual que las Entidades Estatales deben diligenciar, publicar y actualizar en los términos del presente título.

Proceso de Contratación: Conjunto de actos y actividades, y su secuencia, adelantadas por la Entidad Estatal desde la planeación hasta el vencimiento de las garantías de calidad, estabilidad y mantenimiento, o las condiciones de disposición final o recuperación ambiental de las obras o bienes o el vencimiento del plazo, lo que ocurra más tarde.

La importancia de la planeación en esta etapa comporta "[...] la decisión de la Administración de un objeto determinado como la colaboración de un particular o de otra entidad pública requiere de un análisis previo de la necesidad y especificaciones del mismo, la oportunidad y conveniencia en su ejecución" (Expósito Vélez, 2013, p. 50).

Más adelante, el mismo decreto único reglamentario del sector administrativo de la planeación nacional, dedica la sección 2, subsección 2 a la planeación, en los artículos 2.2.1.1.2.1.1. a 2.2.1.1.2.1.5., normas que se resumen en su contenido a continuación:

a) Estudios y documentos previos. Son el soporte para elaborar el proyecto de pliegos, los pliegos de condiciones, y el contrato, son de consulta pública y deben contener en términos generales:

1. La descripción de la necesidad que la Entidad Estatal pretende satisfacer con el Proceso de Contratación.

2. El objeto a contratar, con sus especificaciones, las autorizaciones, permisos y licencias requeridos para su ejecución, y cuando el contrato incluye diseño y construcción, los documentos técnicos para el desarrollo del proyecto.

3. La modalidad de selección del contratista y su justificación, incluyendo los fundamentos jurídicos.

4. El valor estimado del contrato y la justificación del mismo. Cuando el valor del contrato esté determinado por precios unitarios, la Entidad Estatal debe incluir la forma como los calculó y soportar sus cálculos de presupuesto en la estimación de aquellos. La Entidad Estatal no debe publicar las variables utilizadas para calcular el valor estimado del contrato cuando la modalidad de selección del contratista sea en

8. Artículo 74. Plan de acción de las entidades públicas. A partir de la vigencia de la presente ley, todas las entidades del Estado a más tardar el 31 de enero de cada año, deberán publicar en su respectiva página web el Plan de Acción para el año siguiente, en el cual se especificarán los objetivos, las estrategias, los proyectos, las metas, los responsables, los planes generales de compras y la distribución presupuestal de sus proyectos de inversión junto a los indicadores de gestión. A partir del año siguiente, el Plan de Acción deberá estar acompañado del informe de gestión del año inmediatamente anterior. Igualmente publicarán por dicho medio su presupuesto debidamente desagregado, así como las modificaciones a este o a su desagregación. Parágrafo. Las empresas industriales y comerciales del Estado y las Sociedades de Economía Mixta estarán exentas de publicar la información relacionada con sus proyectos de inversión. 
concurso de méritos. Si el contrato es de concesión, la Entidad Estatal no debe publicar el modelo financiero utilizado en su estructuración.

5. Los criterios para seleccionar la oferta más favorable.

6. El análisis de Riesgo y la forma de mitigarlo.

7. Las garantías que la Entidad Estatal contempla exigir en el Proceso de Contratación.

8. La indicación de si el Proceso de Contratación está cobijado por un Acuerdo Comercial.

b) Pliegos de condiciones. (Concordante con el numeral 5 del artículo 24 de la Ley 80 de 1993) Los pliegos de condiciones son aquel acto administrativo mixto (general antes de la contratación y particular una vez se adjudica) que sirve de marco para la adjudicación, celebración, ejecución e interpretación del futuro contrato ${ }^{9}$, al entrar a regular las condiciones que deben llenar los proponentes y las propuestas.

Sobre la interacción del contenido de los pliegos de condiciones y el principio de planeación, nos ilustra la jurisprudencia contenciosa:

No debe perderse de vista que los pliegos de condiciones son clara manifestación de los principios de planeación, transparencia, selección objetiva y de igualdad, ya que en ellos es obligación de la administración establecer reglas y procedimientos claros y justos, que permitan la mejor escogencia del contratista con arreglo a las necesidades públicas y el interés general. (Consejo de Estado, 2013).

Sobre la naturaleza de los pliegos de condiciones, la doctrina comenta:

[...] como acto unilateral de la administración; como reglamento; en su carácter contractual, o de su naturaleza mixta, y ha asumido esta última, dado que una vez adjudicado el proceso muta y se incorpora en su parte pertinente, como parte del contrato, de tal manera que culminada la etapa precontractual, se convierte en cláusula contractual. (González López, 2010, p. 46).

Dentro del contenido que deben tener los pliegos, el reglamento nos determina:

1. Descripción técnica, detallada y completa del bien o servicio objeto del contrato.

2. Modalidad del proceso de selección y su justificación.

3. Criterios de selección, incluyendo los factores de desempate y los incentivos cuando a ello haya lugar.

4. Condiciones de costo y/o calidad que la Entidad Estatal debe tener en cuenta para la selección objetiva, de acuerdo con la modalidad de selección del contratista.

\footnotetext{
9. Conforme a la jurisprudencia reiterada, se aplican por sobre el contenido mismo del contrato. El Consejo de Estado ha dicho: La Sala ha considerado que el pliego es la ley del contrato y, que frente a una contradicción entre el pliego y el contrato, habrá de prevalecer aquél; el pliego, según la jurisprudencia, contiene derechos y obligaciones de los futuros contratantes, quienes no pueden modificar libremente sus disposiciones del pliego en el contrato que han de celebrar. Ahora bien, para precisar el alcance de esta orientación jurisprudencial, conviene tener en cuenta que, en el pliego de condiciones, se distinguen dos grupos normativos: los que rigen el procedimiento de selección del contratista y los que fijan el contenido del contrato que habrá de suscribirse. Respecto del primero la intangibilidad del pliego se impone en desarrollo de los principios que rigen la licitación, tales como el de igualdad, transparencia y de selección objetiva del contratista, bajo el entendido de que sería abiertamente violatorio de los mismos, que la entidad modificara, a su arbitrio, las reglas de la selección. En relación con el segundo grupo, es decir con las normas que establecen las disposiciones jurídico negociables del contrato a celebrarse, la intangibilidad del pliego garantiza la efectividad de los derechos y obligaciones previstos para los futuros co-contratantes. Por tanto, no es procedente modificar ilimitadamente el pliego, mediante la celebración de un contrato que contenga cláusulas ajenas a las previstas en aquél, porque ello comporta una vulneración de las facultades y derechos generados en favor de los sujetos que participan en el procedimiento de selección del contratista: oferentes y entidad. Dicho en otras palabras, la regla general es que adjudicatario y entidad se sometan a lo dispuesto en el pliego de condiciones, incluso respecto del contenido del contrato que han de celebrar, porque el mismo rige no sólo el procedimiento de selección del contratista, sino también los elementos del contrato que ha de celebrarse. Sin embargo, es posible que, con posterioridad a la adjudicación del contrato, se presenten situaciones sobrevinientes, que hagan necesaria la modificación de las cláusulas del contrato, definidas en el pliego. En estos eventos las partes podrían modificar el contenido del contrato, predeterminado en el pliego, siempre que se pruebe la existencia del hecho o acto sobreviniente, que el mismo no sea imputable a las partes y que la modificación no resulte violatoria de los principios que rigen la licitación, ni los derechos generados en favor de la entidad y el adjudicatario. Consejo de Estado, Sección Tercera, sentencia del 29 de enero de 2004, exp. 10779, M.P. Alier E. Hernández Enríquez. Reiterada en: Consejo de Estado. Sala de lo Contencioso Administrativo. Sección Tercera. Subsección C. Consejero Ponente: Enrique Gil Botero. Sentencia del 24 de julio de 2013. Radicación Número: 05001-23-31-000-1998-00833-01(25642). Actor: Andina De Construcciones Ltda. Demandado: Municipio de Rionegro y Otros. Referencia: Acción de Nulidad y Restablecimiento del Derecho -Contractual-.
} 
5. Reglas aplicables a la presentación de las ofertas, su evaluación y a la adjudicación del contrato.

6. Causas que dan lugar a rechazar una oferta.

7. Valor del contrato, el plazo, el cronograma de pagos y la determinación de si debe haber lugar a la entrega de anticipo, y si hubiere, indicar su valor, el cual debe tener en cuenta los rendimientos que este pueda generar.

8. Riesgos asociados al contrato, la forma de mitigarlos y la asignación del Riesgo entre las partes contratantes.

9. Garantías exigidas en el Proceso de Contratación y sus condiciones.

10. Mención de si la Entidad Estatal y el contrato objeto de los pliegos de condiciones están cubiertos por un Acuerdo Comercial.

11. Términos, condiciones y minuta del contrato.

12. Términos de la supervisión y/o de la interventoría del contrato.

13. Plazo dentro del cual la Entidad Estatal puede expedir Adendas.

14. Cronograma del proceso de selección que incluye la fecha de adjudicación y suscripción del futuro contrato.

c) Observaciones al proyecto de pliegos de condiciones. Los interesados (futuros proponente o comunidad en general por el interés público que comporta la contratación estatal) pueden hacer comentarios al proyecto de pliegos de condiciones a partir de la fecha de publicación de los mismos, durante un término de 10 días hábiles en la licitación pública y durante un término de 5 días hábiles en la selección abreviada y el concurso de méritos.

d) Acto administrativo de apertura del proceso de selección. Es el acto que da inicio al proceso de selección y materializa toda la etapa de planeación previa. Se caracteriza este acto administrativo por ser de carácter general y debe contener:

1. Objeto de la contratación a realizar.

2. Modalidad de selección que corresponda a la contratación.

\section{Cronograma.}

4. Lugar físico o electrónico en que se puede consultar y retirar los pliegos de condiciones y los estudios y documentos previos (principio de publicidad).

5. Convocatoria para las veedurías ciudadanas (principio de participación).

6. Certificado de disponibilidad presupuestal, en concordancia con las normas orgánicas correspondientes (Componente presupuestal de la planeación).

7. Los demás asuntos que se consideren pertinentes de acuerdo con cada una de las modalidades de selección. 


\section{Contenido presupuestal del principio de planeación:}

Hemos dejado aparte el contenido presupuestal del principio de planeación, por la importancia jurídica y administrativa del presupuesto, como herramienta de control y gestión de las entidades públicas. Como explica la doctrina:

En lo que atañe al desarrollo del Estatuto Orgánico del presupuesto General de la Nación debe analizarse lo dicho en principio sobre la relación de la planeación en la contratación estatal con la perspectiva genérica, por lo cual todo gasto en que incurra el Estado debe estar previamente autorizado por la Ley de Presupuesto Nacional y la de cada entidad respectiva. (Expósito Vélez, 2003, p. 593)

Conforme con las normas contractuales y de presupuesto, solo se dará inicio al proceso de selección cuando exista la disponibilidad presupuestal para ello (artículo 25 numeral 6 de la Ley 80 de 1993) y de forma expresa nos regula la norma orgánica del presupuesto, compilada en el Decreto 111 de 1996:

Artículo 12. Los principios del sistema presupuestal son: la planificación, la anualidad, la universalidad, la unidad de caja, la programación integral, la especialización, inembargabilidad, la coherencia macroeconómica y la homeostasis (Ley 38 de 1989, artículo 8 y Ley 179 de 1994, artículo 4).

Artículo 13. Planificación. El Presupuesto General de la Nación deberá guardar concordancia con los contenidos del Plan Nacional de Desarrollo, del Plan Nacional de Inversiones, del Plan Financiero y del Plan Operativo Anual de Inversiones (Ley 38 de 1989, artículo 9 y Ley 179 de 1994, artículo 5).

Sobre este aspecto, la doctrina los ilustra:

Esto demuestra la necesaria e indisoluble conexión que existe entre la planeación en materia financiera respecto de los gastos del Estado y la planificación de los contratos estales; así, para que un contrato pueda llevarse a cabo debe contar con la partida presupuestal, la cual solo existirá en la medida en que la Ley de Presupuesto así lo autorice, todo de acuerdo con el Plan Nacional de Desarrollo; de modo que la contratación pública configura como uno de los mecanismos más importantes para su realización. (Expósito Vélez, 2003, p. 593)

Así pues, las normas contractuales, presupuestales y de planeación de la administración, se deben acoplar para dar lugar al inicio de la actividad contractual del Estado, en la búsqueda de los fines Estatales.

Como podemos observar, la constitución, la ley, el reglamento y la jurisprudencia, son amplios en definir el principio de planeación como fundamento esencial de la contratación estatal y soporte fundamental para el inicio del procedimiento administrativo contractual o proceso de selección del contratista en las diferentes modalidades. Pero como se desarrolla a continuación, la planeación no solo se refleja en esta etapa de inicio o precontractual, sino que irriga todas las demás de la contratación estatal.

\section{El principio de planeación en la etapa contractual:}

Como estudiamos, la planeación nace en la etapa pre contractual, pero esta de forma necesaria incide en la etapa de formación, ejecución y cumplimiento del contrato. Sobre este aspecto la doctrina nos enseña:

La falta de planeación del contrato no sólo se refleja en la etapa de formación, sino también en la fase de cumplimiento de las prestaciones recíprocas, donde las omisiones de la Administración Pública afectarán sensiblemente el interés público de la comunidad y la economía del contrato. 
Siempre, como regla general, la falta de estudios serios y completos en torno a los bienes objeto del contrato ocasiona graves obstáculos durante su ejecución, especialmente en los de obra pública y concesión de servicios públicos, donde se presentará la necesidad de paralizar el proyecto, mientras se elaboran y deciden por las instancias competentes los planes y diseños definitivos; o será necesario proceder a una modificación de las cantidades de obra y especificaciones técnicas inicialmente acordadas; o finalmente conllevará la frustración del proyecto por la aparición de dificultades que debieron preverse al momento de evaluarse la conveniencia u oportunidad del contrato.

La falta de los estudios técnicos previos se traduce en un mayor valor del contrato, que necesariamente se imputará al tesoro público, por las mayores erogaciones y gastos que deberá asumir el contratista, derivados de una mayor permanencia en el lugar de los trabajos, con los sobrecostos que esta situación genera en gastos de administración, mano de obra, maquinaria y equipo, incremento de los costos de los factores determinantes del precio, etc. Además, los cambios y modificaciones de los diseños y especificaciones técnicas se reflejan en la necesidad de realizar obras adicionales que encarecerán la ejecución del proyecto. Estos problemas, colocan a la administración y a su colaborador privado ante una razonable imposibilidad de ejecutar el contrato, cuando no se frustra la realización del proyecto por dificultades técnicas que pudieron conocerse anticipadamente. (Escobar Gil, 1999, p.71-72).

Igualmente, Dávila Vinueza (2003) afirma que la fase preparatoria del proceso de selección del contratista resulta ser de gran importancia, pues los errores que en ella se comenten inciden de forma negativa en la ejecución del contrato, pues las falencias en la planeación general demoras por la ausencia de requisitos o condiciones necesarias para el cumplimiento de su objeto, de donde se reitera la incidencia del principio en estudio en todas las etapas del contrato, incluida su ejecución.

Así, en la ejecución del contrato, incide de forma directa la planeación previa del contrato, y para ello se ha consagrado por parte de la ley un importante instrumento para verificar de forma permanente la ejecución del contrato como lo es la supervisión o interventoría del contrato estatal. El artículo 83 de la Ley 1474 de 2011 consagra al respecto que esta figura posee como objetivo la protección de la moralidad administrativa como principio que irradia el actuar de la administración pública a fin de prevenir los actos de corrupción y velar por la transparencia de la actividad contractual, por lo que es menester que se vigile de forma permanente la ejecución del contrato a través de una de las dos figuras, valga reiterar, la supervisión y la interventoría.

La anterior norma referida es importante, dado que la planeación contractual incide de forma directa en la ejecución del contrato (etapa contractual), puesto que dentro de las principales funciones de la supervisión o interventoría se encuentra la de propender por que el contrato se desarrolle o ejecute de forma oportuna y dentro de los tiempos consagrados en los cronogramas que se encuentran soportados dentro de los documentos previos del contrato, ya estudiados, que constituyen la etapa precontractual de planeación. Conforme lo estudia la doctrina:

A pesar de las pocas referencias que el Estatuto Contractual hace expresamente al Interventor, la importancia de este en la relación negocial estatal es determinante. Su intervención en todos los contratos estatales garantiza una correcta verificación de la inversión de los dineros públicos, la adecuada ejecución del objeto negocial y con ello, la cabal satisfacción de los fines del Estado. (Rico Puerta, 2018, p. 874).

Más adelante, el mismo autor nos ilustra sobre las funciones de este en torno, o realizada con soporte a, la planeación contractual, la que se cumple concretamente frente a la ejecución de las obligaciones reciprocas que el contrato estatal consagra, específicamente referentes ellas a verificar la materialización del régimen del equilibrio económico del contrato (igualdad o equivalencia entre derechos y obligaciones), 
el sostenimiento de las condiciones técnicas, económicas, financieras del contrato en su ejecución y liquidación; suscripción de los documentos de avance en la ejecución del contrato y el cumplimiento de las obligaciones reciprocas, y verificar los pago por parte de la entidad y la correcta ejecución de las obras, inversión y ejecución técnica del contrato. (Rico Puerta, 2018, p. 877 y 878).

Por lo dicho, el supervisor o interventor, debe constantemente estar evaluando, controlando, verificando e identificando la materialización de alguno de los riesgos identificados en la etapa de planeación contractual, para de esta forma en la ejecución del contrato, estar atentos en la adopción de medidas que controlen, aminoren o mitiguen los riesgos inherentes al contrato y previamente distribuidos, y así lograr que el contrato llegue a feliz término y materialice los fines estatales que pretende solventar.

Desarrollado ya este primer aspecto, pasamos a abordar el tema de las causales de anulabilidad absoluta del contrato estatal.

\section{Causales de anulabilidad absoluta del contrato estatal}

Se parte de la base que la contratación estatal posee unas características especiales que la diferencian de la contratación entre privados, por lo que el constituyente ordenó al legislador colombiano expedir el estatuto general de contratación estatal de la administración pública (inciso final del artículo 150 de la C.P. que regula el campo de acción del congreso a través de las leyes).

No obstante, lo dicho, el mismo estatuto general de contratación consagra unas remisiones generales y especiales a las normas que regulan las obligaciones y los contratos civiles y comerciales, así: El inciso primero del artículo 13 de la Ley 80 de 1993 consagra de forma clara:

Artículo $13^{\circ}$.- De la Normatividad Aplicable a los Contratos Estatales. Los contratos que celebren las entidades a que se refiere el artículo 2 del presente estatuto se regirán por las disposiciones comerciales y civiles pertinentes, salvo en las materias particularmente reguladas en esta Ley.

Adicionalmente, el artículo 44 ibídem, consagra unas causales de nulidad absoluta del contrato estatal, además de las consagradas en el derecho común, entendido por este el derecho civil y comercial, así:

Artículo 44‥- De las Causales de Nulidad Absoluta. Los contratos del Estado son absolutamente nulos en los casos previstos en el derecho común y además cuando:

10. Se celebren con personas incursas en causales de inhabilidad o incompatibilidad previstas en la Constitución y la ley;

2o. Se celebren contra expresa prohibición constitucional o legal.

3o. Se celebren con abuso o desviación de poder.

4o. Se declaren nulos los actos administrativos en que se fundamenten; y

5o. Se hubieren celebrado con desconocimiento de los criterios previstos en el artículo 21 sobre tratamiento de ofertas nacionales y extranjeras o con violación de la reciprocidad de que trata esta Ley.

Por ello, la norma en comento consagra 5 causales especiales de nulidad absoluta del contrato estatal y el inciso primera remite a las normas que regulan dicha institución contractual en el derecho común (se reitera, Códigos Civil y de Comercio). De la primera de las codificaciones mencionadas, se destaca: 
Artículo 1519. Objeto ilícito. Hay un objeto ilícito en todo lo que contraviene al derecho público de la nación. Así, la promesa de someterse en la república a una jurisdicción no reconocida por las leyes de ella, es nula por el vicio del objeto.

Artículo 1523. Objeto ilícito por contrato prohibido. Hay así mismo objeto ilícito en todo contrato prohibido por las leyes.

Artículo 1524. Causa de las obligaciones. No puede haber obligación sin una causa real y lícita; pero no es necesario expresarla. La pura liberalidad o beneficencia es causa suficiente.

Se entiende por causa el motivo que induce al acto o contrato; y por causa ilícita la prohibida por la ley, o contraria a las buenas costumbres o al orden público.

Así, la promesa de dar algo en pago de una deuda que no existe, carece de causa; y la promesa de dar algo en recompensa de un crimen o de un hecho inmoral, tiene una causa ilícita.

Artículo 1740. Concepto y clases de nulidad. Es nulo todo acto o contrato a que falta alguno de los requisitos que la ley prescribe para el valor del mismo acto o contrato según su especie y la calidad o estado de las partes.

\section{La nulidad puede ser absoluta o relativa}

Artículo 1741. Nulidad absoluta y relativa. La nulidad producida por un objeto o causa ilícita, y la nulidad producida por la omisión de algún requisito o formalidad que las leyes prescriben para el valor de ciertos actos o contratos en consideración a la naturaleza de ellos, y no a la calidad o estado de las personas que los ejecutan o acuerdan, son nulidades absolutas.

Hay así misma nulidad absoluta en los actos y contratos de personas absolutamente incapaces.

Cualquiera otra especie de vicio produce nulidad relativa, y da derecho a la rescisión del acto o contrato.

Artículo 1742. Obligación de declarar la nulidad absoluta. Subrogado por el artículo 2 de la Ley 50 de 1936. El nuevo texto es el siguiente: La nulidad absoluta puede y debe ser declarada por el juez, aún sin petición de parte, cuando aparezca de manifiesto en el acto o contrato; puede alegarse por todo el que tenga interés en ello; puede así mismo pedirse su declaración por el ministerio público en el interés de la moral o de la ley. Cuando no es generada por objeto o causa ilícitos, puede sanearse por la ratificación de las partes y en todo caso por prescripción extraordinaria.

Del Código de Comercio, se trae a colación:

Artículo 899. Nulidad absoluta. Será nulo absolutamente el negocio jurídico en los siguientes casos:

1) Cuando contraría una norma imperativa, salvo que la ley disponga otra

cosa;

2) Cuando tenga causa u objeto ilícitos, y

3) Cuando se haya celebrado por persona absolutamente incapaz. 
Sobre el tema, Rico (2018) afirma que el régimen de anulabilidad del contrato estatal es mixto en cuanto a sus causales, pues: "El examen sobre la anulabilidad del Contrato Estatal, comporta el de las causales expresamente consagradas en la Ley 80 de 1993, en el C.C. y en el Código de Comercio." (Rico Puerta, 2018, p. 967).

Empecemos el análisis de las causales especiales de anulabilidad absoluta consagradas en la norma del estatuto contractual público:

Se celebren con personas incursas en causales de inhabilidad o incompatibilidad previstas en la Constitución y la ley

Para fijar el alcance de esta causal de anulabilidad del contrato estatal debe acudirse a las normas especiales que consagran las inhabilidades e incompatibilidades.

En primer lugar, la inhabilidad es entendida como una serie de hechos que de aparecer, impiden el legal ejercicio de un derecho (acceso al cargo o contratación estatal, por ejemplo) dado que de presentarse, los mismos afectan la voluntad del pueblo o del ente contratante, el ejercicio adecuado del poder y la moralidad pública. En otras palabras, son un cúmulo de circunstancias descritas en la ley que imposibilitan o limitan el libre actuar de las personas.

La jurisprudencia constitucional en múltiples oportunidades, además de la sentencia objeto de este escrito, ha abordado el tema, por ser este de vital importancia en el ejercicio del poder Estatal, y ha definido las inhabilidades como:

6. Aparte de unificar las reglas básicas de la actividad política, no debe olvidarse que el régimen de inhabilidades al cual se sujeta el acceso al ejercicio del poder político, persigue el respeto y prevalencia de los intereses generales, la igualdad, la moralidad y la imparcialidad, que se verían comprometidos si se dejaran de consagrar determinadas y específicas causales de inelegibilidad, como la que es materia de análisis. (Corte Constitucional, 1995)

Por su parte, la incompatibilidad es la imposibilidad jurídica de que coexistan dos actividades (Corte Constitucional, sentencia C-349 de 1994), en otras palabras, es la limitación impuesta al servidor público durante ejercicio de su cargo (Corte Constitucional, sentencia C-329 de 1995).

Así pues, relacionando estos dos conceptos generales a la luz de la Constitución Política, el artículo 8 de la Ley 80 de 1993 y demás normas especiales que consagran este tipo de circunstancias que limitan la capacidad contractual para efectos de favorecer o beneficiar el interés general y la moralidad administrativa por sobre los intereses de las parte del contrato, son ambas prohibiciones y como se dijo, limitaciones a la libertad contractual, por lo que su regulación normativa es muy importante, pues al limitar un derecho, se exige que sea el legislador el que defina dichas circunstancias de forma expresa y clara, por lo que ellas son de interpretación restrictiva, de régimen taxativo y expreso, de imposible interpretación amplia y proscrita su aplicación analógica, y la incompetencia de regular este tipo de situaciones a través del reglamento, el pliego de condiciones o las condiciones contractuales ${ }^{10}$, es decir, sujeto este tema a reserva de ley ${ }^{11}$.

Así pues, los conceptos de inhabilidad e incompatibilidades a la luz de la contratación estatal, podemos concluir que estas figuras aparecen en la contratación estatal de forma diferente, así:

10. Ver Consejo de Estado. Sala de lo Contencioso Administrativo. Sección Tercera. Sentencia del 3 de diciembre de 2007. Consejera Ponente Ruth Stella Correa Palacio. Expediente 24715.

11 Ver Sierra P., H.A. (1998). Concepto y tipos de ley en la constitución colombiana. Bogotá: Universidad Externado de Colombia. 
- Las primeras se dirigen a describir situaciones fácticas frente al contratista y las segundas a la entidad estatal contratante o a las personas que las representan en cargos de dirección y control de la misma.

- Las primeras son actos anteriores a la actividad contractual e imposibilitan su materialización y las segundas son concomitantes a la misma y la repelen.

- Las incompatibilidades son las limitaciones de la capacidad contractual de forma específica y las inhabilidades de forma general frente a la entidad con la que se va a contratar.

- Por último, en el aspecto temporal, las incompatibilidades son concomitante o subsiguiente al negocio jurídico, mientras que las inhabilidades son anteriores a la celebración del negocio jurídico, sin que obste que se presente de forma sobreviniente.

Como aspectos similares tenemos:

- Ambas favorecen o benefician el interés general, la moralidad administrativa, la transparencia, la objetividad y la imparcialidad, por sobre los intereses de las partes del contrato.

- Son ambas prohibiciones, limitaciones a la libertad contractual.

- Su regulación normativa se encuentra sujeta a reserva de ley.

- Su interpretación es restrictiva, su régimen taxativo y expreso, y en su aplicación se encuentra proscrita la analogía o interpretación extensiva.

- Su trasgresión trae como consecuencia la posible responsabilidad penal y disciplinaria, y desde el punto de vista contractual se afecta la capacidad de contratación y la validez del contrato, generando su nulidad absoluta.

\section{Se celebren contra expresa prohibición constitucional o legal}

Como se ha explicado, la actividad contractual de la administración (en sentido orgánico) se sujeta al principio de legalidad (artículos 6 y 121 de la C.P.) por lo que los contratos expresamente prohibidos por la Constitución y la ley se encuentran afectados de un vicio de anulabilidad absoluta.

Igual que la anterior causal, la cual está descrita en términos generales y habrá de acudirse a las normas especiales que regulen de forma expresa esta prohibición. En la tipología de causales de anulación del contrato en el Código Civil (artículos 1519, 1523 y 1524, ya traídos a colación) esta se encuentra descrita como objeto o causa ilícita, si la prohibición legal se enmarca en la materia del contrato o en su móvil, respectivamente. En la tipología de causales de anulación del Código de Comercio, los encontramos en los numerales 1 y 2 del artículo 899. Estudiada esta causal por la doctrina, nos ilustra:

Cabe agregar, que la falsa motivación del contrato estatal como causal de anulabilidad, tiene una relación directa con la etapa precontractual, y con todos y cada uno de los sistemas de planeación por ser estos elementos integrantes del principio de responsabilidad por la gestión negocial pública. En consecuencia, la falsa motivación del contrato estatal tiene su génesis inmediata en los estudios previos, en la etapa prenegocial, dado que en ella, el Estado debe hacer un exacto análisis de la realidad que va a resolver con el contrato mismo. (Rico Puerta, 2018, p. 974) 


\section{Se celebren con abuso o desviación de poder}

Esta causal se confunde con la anteriormente desarrollada, dado que incluye un vicio en el móvil de la contratación (causa), pues el abuso o desvió de poder ha sido interpretado por la jurisprudencia como: "La utilización de los poderes, atribuciones o competencias para el logro de una finalidad contraria a los fines para los cuales se otorgaron." (Consejo de Estado, 2016, p. 24).

En otras palabras, el contrato no busca materializar los fines estatales y se sujeta al principio de legalidad, sino fines e intereses subjetivos y desviados.

\section{Se declaren nulos los actos administrativos en que se fundamenten}

Causal específicamente aplicable a la contratación estatal que como se ha reiterado en el presente trabajo, es reglada, es decir, la administración no escoge libremente a su contratista, sino que realiza un procedimiento previo para selección al proponente que presente una mejor propuesta y demuestre idoneidad para su ejecución. Por ello, en el trámite del proceso de selección se dicta varios actos administrativos pre contractuales (entendidos por estos los dictados en esta etapa previa a la celebración del contrato) como son a título de ejemplo los pliegos de condiciones, el acto de apertura del proceso de selección, el acto de adjudicación del contrato. Así pues, cuando estos actos, que soportan la actividad contractual y la celebración, perfeccionamiento y posterior ejecución del contrato estatal, se anulan por parte de la jurisdicción contencioso administrativa, el contrato estatal que de ellos deviene incurre en esta causal de anulabilidad absoluta.

\section{Se hubieren celebrado con desconocimiento de los criterios previstos en el artículo 21 sobre tratamiento de ofertas nacionales y extranjeras o con violación de la reciprocidad de que trata esta ley}

Esta causal, igualmente, no es otra cosa que el desarrollo concreto de la segunda de las causales (Se celebren contra expresa prohibición constitucional o legal) y por ello devendría el contrato en nulo por objeto o causa ilícita.

Desarrolladas pues como están las causales de anulabilidad del contrato estatal consagradas por la Ley 80 de 1993, se pasa a analizar la forma cómo la jurisdicción contencioso administrativa ha abordado el tema de la violación del principio de planeación como causal de anulabilidad del contrato estatal, es decir, cómo se relacionan los dos acápites que anteceden.

\section{Línea jurisprudencial del Consejo de Estado sobre la violación del principio de planeación contractual como causal de anulabilidad absoluta del contrato estatal. (Análisis estático y dinámico):}

Dentro del sistema normativo colombiano es innegable la importancia actual de la jurisprudencia como fuente formal del derecho. Por ello, se hace necesario que cualquier tópico que se emprenda, se estudie desde la perspectiva que lo ha abordado la jurisprudencia, en especial la de las altas cortes, atendiendo la calidad de fuente formal del derecho con obligatoriedad relativa ${ }^{12}$, por lo que es menester que se analice el tema en concreto de la violación del principio de planeación y sus consecuencias frente a la validez del contrato y estudiando las diferentes posiciones encontradas en la jurisprudencia se utilizarán las técnicas

\footnotetext{
12. En este punto, es importante tener presente las sentencias de la Corte Constitucional sobre el tema, en especial las decisiones SU-047 de 1999 y C-836 de 2001 , las que definieron y determinaron de forma clara el valor de la jurisprudencia como fuente del derecho. Igualmente, es necesario tener presente que la ley reconoce de forma expresa el valor del precedente jurisprudencial como fuente principal del derecho, dentro de las cuales se destacan:

- Ley 1437 de 2011, por la cual se adopta el Código de Procedimiento Administrativo y de lo Contencioso Administrativo, artículos 10, 102, 256 a 269.

- $\quad$ Ley 1564 de 2012, por el cual se adopta del Código General del Proceso, artículos 7, 35 y 42 numeral 7.
} 
de análisis estático ${ }^{13}$ y dinámico ${ }^{14}$ de las sentencias para el abordaje del tema desde el punto de vista del precedente judicial, con el fin de estructurar la argumentación realizada por las decisiones judiciales al respecto y definir cuál es la consecuencia de la violación del principio mencionado.

La importancia de analizar esta línea jurisprudencial la encontramos en la misma doctrina especializada sobre el tema, la que nos indica:

Si bien existen varias sentencias en las que el máximo tribunal de lo contencioso administrativo ha declarado la nulidad absoluta de contratos estatales por violación del deber de planeación, es menester aclarar que la jurisprudencia en este punto es ambivalente. En efecto, también se ha pronunciado el Consejo de Estado en el sentido de declarar la existencia de incumplimientos contractuales de la entidad estatal contratante por violación de este principio. (Deik Acostamadiedo, 2014, p. 39).

Entremos pues a realizar el análisis propuesto, aclarando que se identifican en el texto del presente proyecto las sentencias más importantes y se presenta el análisis dinámico de las sentencias analizadas:

\section{Análisis estático}

Todas las decisiones aludidas poseen una estructura similar y parten de la aceptación general de la importancia de la planeación en la contratación estatal, tal como se ha expuesto previamente en el presente trabajo. Realizada la anterior aclaración, se pasará a clasificar las sentencias referenciadas, tomando como base la diferenciación que de las sentencias que conforma una línea jurisprudencia hace el profesor Diego Eduardo López Medina ${ }^{15}$ :

Sentencia arquimédica: Se toma como sentencia arquimédica, entendida esta como "... una sentencia con la que el investigador tratará de desenredar las relaciones estructurales entre varias sentencias." (López, 2006, p. 132) la más reciente encontrada sobre el tema, por lo que sirvió como tal la sentencia dictada dentro del proceso conocido por el Consejo de Estado, Sala de lo Contencioso Administrativo, Sección Tercera, Subsección C, Consejero Ponente: Jaime Orlando Santofimio Gamboa, de fecha 23 de octubre de 2017, radicación número 15001233300020130052601 (55855), actor Ingenieros G.F. S.A.S., demandado Departamento de Boyacá.

Sentencia hito: Se toma como sentencias hito, entendida como tal la que “...trata de definir con autoridad una sub-regla de derecho constitucional." (López, 2006, p. 148) la sentencia dictada por el Consejo de Estado, Sala de lo Contencioso Administrativo, Sección Tercera, Subsección C, Consejero Ponente: Jaime Orlando Santofimio Gamboa, de fecha 24 de abril de 2013, radicación número 68001231500019980174301 (27315), actor Jairo Ospina Cano, demandado Área Metropolitana de Bucaramanga; atendiendo que fue la primera que definió de forma clara que la violación del principio de planeación da al traste con el contrato viciándolo de nulidad absoluta.

Sentencia fundadora de la línea: Se clasifica como sentencia fundadora de la línea, entendida como tales aquellas que inician la línea que se estudia, la sentencia previamente citada en el anterior numeral.

Sentencias reiteradoras de la línea: Como se indicó, solo existen dos sentencias que desarrollan de forma concreta el tema bajo escrutinio.

\footnotetext{
13. Entendemos por análisis estático de las sentencias, con fundamento en la doctrina explicada por López (2006), el estudio de la estructura interna, lógica y argumentativa de la decisión judicial, realizando para ello una disección de la misma para identificar el problema jurídico que aborda, el argumento central con el que se responde (ratio decidendi), los subargumentos (obiter dictum) y la parte resolutiva (decisum).

14. Por análisis dinámico entendemos, igualmente siguiendo la doctrina elaborada por el profesor López (2006), la construcción de una línea jurisprudencial en donde se interrelacionan las diferentes decisiones previamente analizadas estáticamente, para identificar dentro de ella las posturas que se adoptan en torno al mismo problema jurídico, fijando así las diversas posiciones y determinar si se ha estructurado una línea uniforme, controversial o caótica, al momento de definir el mismo problema jurídico.

15. López, D.E. (2006). El derecho de los jueces. Bogotá: Legis S.A., p.161 a 167. Del mismo autor, (2006) Interpretación Constitucional. Bogotá Consejo Superior de la Judicatura, p. 131 a 138.
} 


\section{Análisis dinámico}

Realizado el correspondiente rastreo de la jurisprudencia existente en las bases de datos jurídicas, la página web del Consejo de Estado y las publicaciones especializadas sobre el tema de la contratación estatal, encontramos en torno al problema de investigación, que es planteado igualmente como problema jurídico que encabeza la línea jurisprudencial a elaborar, un total de siete (7) sentencias que dan respuesta de forma directa al mismo, hallando que se responde a este de dos formas totalmente opuestas así:

- Llamaremos primera posición, la que se inclina a afirmar que la trasgresión del principio de planeación por parte de la entidad pública comporta la nulidad absoluta del contrato estatal, la que en el cuatro se encuentra a mano izquierda del lector; y como segunda la que niega dicha consecuencia, la que se encuentra a mano derecha del lector.

- La primera posición es adoptada por el máximo juez de lo contencioso administrativo especializado en las materias contractuales, pues la Sección Tercera de la Sala Plena Contencioso Administrativo del Consejo de Estado, es la que reglamentariamente le compete conocer de este tipo de procesos (artículo 13 del Acuerdo 58 de 1999, modificado por el artículo 1 del Acuerdo 55 de 2003 de la Sala Plena del Consejo de Estado).

- La segunda posición, se ve reflejada en dos decisiones de la Sección Cuarta y la Sección Quinta de la Sala Contencioso Administrativa del Consejo de Estado, quienes decidieron acciones de tutela en contra de una providencia de la sección especializada.

Ejecutada la correspondiente clasificación de las sentencias a estudiar, se realizó el análisis de las mismas, es decir, la disección de los argumentos presentados en torno al problema jurídico abordado y se presentan gráficamente los resultados del estudio elaborado a cada sentencia, en el siguiente cuadro:

Línea jurisprudencial Consejo de Estado, consecuencias de la transgresión del principio de planeación contractual por parte del ente público contratante frente a la anulabilidad absoluta del contrato estatal. Fuente: Elaboración propia.

\section{Conclusiones}

En torno al principio de planeación:

La constitución, la ley, el reglamento, la doctrina y la jurisprudencia, son amplios en definir el principio de planeación como fundamento esencial de la contratación estatal y soporte fundamental para el inicio del procedimiento administrativo contractual o proceso de selección del contratista en las diferentes modalidades, y como soporte de la ejecución y cumplimiento del contrato, incidiendo así en todas las etapas de la actividad contratación de la administración pública.

El principio de planeación aparece en la contratación estatal en todas las etapas del procedimiento contractual (pre, contractual y pos contractual) siendo la principal etapa en donde se materializa el mismo la pre contractual, pues ella será la base de la futura contratación y servirá de fundamento para su ejecución y posterior liquidación.

El principio de planeación posee un contenido amplio desarrollado en un marco jurídico complejo, incluido no solo en las normas de contratación estatal, sino también en las normas de planeación como figura propia de la administración en general y la pública en particular y las de presupuesto, como herramienta importante de la planeación pública. 
Por lo anterior, la planeación contractual se encuentra atada de manera directa al principio de legalidad puesto que la actividad contractual del Estado es una de las principales manifestaciones de la actividad de la administración, dado que a través de ella, como se ha reiterado, se busca materializar los fines estatales (la búsqueda del bienestar general y la materialización de los derechos de las personas) y los objetivos concretos de la entidad pública contratante, por lo que a través de la misma se busca en igualdad de condiciones al colaborador estatal (el contratista) a fin de adjudicar el contrato, por regla general, a quien presente la mejor propuesta al Estado.

Cuando hablamos de la contratación estatal, es claro que nos estamos refiriendo a una actividad reglada de la administración, es decir, por regla general el contratante estatal no puede escoger de forma libre, voluntaria y mucho menos arbitraria a su colaborador, pues conforme lo consagra la constitución de forma general (artículo 6 y 121 de la C.P.) y de forma concreta para la contratación de la administración pública (artículo 150 inciso final ibídem) es una función que se encuentra ampliamente regulada en la ley (en sentido material, como reserva de ley) y en sentido amplio (incluyendo los reglamentos).

Así pues, la administración pública (en este caso, esta debe ser entendida como función y no como órgano, para efectos contractuales) se encuentra sujeta a la reglamentación legal existente, pero en este aspecto se señala que la reglamentación mencionada, por una parte, consagra una serie de requisitos y regulaciones previos a la necesidad de contratar, concomitantes a ella, una serie de facultades para reglamentar de forma concreta el proceso de selección (en pliegos de condiciones como acto administrativo mixto, en principio general, que regula de forma concreta el proceso de selección) y la autotutela administrativa de que se dota al momento de definir quién es el beneficiado con el proceso de selección (acto administrativo de selección o adjudicación del contratista, acto administrativo que declara desierto el proceso de selección).

El principio de planeación se llena de contenido con el principio de legalidad y todas las fuentes formales principales del derecho (leyes, reglamentos y fuentes jurisprudenciales) que previamente se han estudiado.

Como se mencionó, la primera posición ha sido adoptada de forma reiterada por la sección especializada en materias de contratación estatal y la segunda por las secciones cuarta y quinta conociendo un proceso en ejercicio de la acción de tutela en contra de una sentencia de la sección tercera.

La primera posición parte de la base de la importancia de la etapa de planeación en la selección del contratista y posterior ejecución del contrato, y en la interpretación de que la planeación inadecuada vicia el objeto contractual de ilicitud por atentar contra una norma de orden público.

En torno a la línea jurisprudencial elaborada:

Existes dos posiciones entorno al problema jurídico planteado, que se identifica con el problema de la presente investigación (¿La transgresión del principio de planeación contractual por parte del ente público contratante puede enmarcarse dentro de una de las causales de nulidad absoluta del contrato estatal?). Llamaremos primera posición, la que se inclina a afirmar que la trasgresión del principio de planeación por parte de la entidad pública comporta la nulidad absoluta del contrato estatal, y como segunda la que niega dicha consecuencia.

La primera posición es adoptada por el máximo juez de lo contencioso administrativo especializado en las materias contractuales, pues la Sección Tercera de la Sala Plena Contencioso Administrativo del Consejo de Estado, es la que reglamentariamente le compete conocer de este tipo de procesos (artículo 13 del Acuerdo 58 de 1999, modificado por el artículo 1 del Acuerdo 55 de 2003 de la Sala Plena del Consejo de Estado). 
La segunda posición, se ve reflejada en dos decisiones de la Sección Cuarta y la Sección Quinta de la Sala Contencioso Administrativa del Consejo de Estado, quienes decidieron acciones de tutela en contra de una providencia de la sección especializada.

La primera posición parte de la base de la importancia de la etapa de planeación en la selección del contratista y posterior ejecución del contrato, y en la interpretación de que la planeación inadecuada vicia el objeto contractual de ilicitud por atentar contra una norma de orden público. En este aspecto se aclara que en esta interpretación, no se trata de cualquier omisión intrascendente de las normas que desarrollan el principio en estudio, sino de una inadecuada planeación contractual que imposibilite la ejecución adecuada del contrato, ya sea desde los aspectos técnicos, jurídicos o financieros.

La segunda posición, analiza el objeto ilícito como el expresamente prohibido por la ley, por ello considera que la trasgresión de la planeación no comporta esta causal de anulabilidad del contrato estatal.

A la luz de las normas de la contratación estatal que desarrollan el principio de planeación, estudiadas en el acápite pertinente, la posición que realiza un análisis, interpretación y aplicación conforme a la constitución, el objeto y teleología de la contratación estatal, es claramente la primera posición adoptada por el juez natural del contrato estatal, la Sección Tercera de la Sala Contencioso Administrativa del Consejo de Estado, pues le da el peso adecuado al principio de planeación, pues su trasgresión claramente vicia el objeto o la causa del contrato estatal al carecer de los soportes previos necesarios para determinar la necesidad, oportunidad y conveniencia de la futura contratación y por ello se enmarca en la causal de anulabilidad del contrato consagrada en el artículo 2 y 3 del artículo 44 de la Ley 80 de 1993 en concordancia con los artículos 1519, 1523, 1524, 1742 del Código Civil y 899 numerales 1 y 2 del Código de Comercio, normas estas estudiadas con anterioridad.

La posición dos, realiza una interpretación aislada de las causales de anulación del contrato, es decir, de las normas citadas en el punto anterior, sin tener en cuenta el desarrollo y alcance concreto del principio de planeación y su trascendencia en la celebración y ejecución del contrato.

La primera posición posee el apoyo de cinco (5) sentencias de la Sección Tercera como juez especializado de las materias contractuales, por lo que a la luz de la doctrina probable es la posición que posee más peso al interior del Consejo de Estado, por ello es la que debe ser la guía de acción de toda la jurisdicción de lo contencioso administrativo.

En torno a la pregunta concreta de investigación:

La transgresión del principio de planeación contractual por parte del ente público contratante, en la medida que la misma imposibilite la ejecución adecuada del contrato, ya sea desde los aspectos técnicos, jurídicos o financieros, es una causal de nulidad absoluta del contrato estatal, y ello tiene como soporte en todas las normas previamente estudiadas que dan alcance y contenido al principio en estudio, posee su soporte en la línea jurisprudencial elaborada la que constituye una posición reiterada en cinco (5) sentencias del juez especializado en la contratación estatal y por ello esta posición comporta la existencia de doctrina probable sobre el tema, y su respuesta negativa solo es una posición aislada adoptada por el Consejo de Estado en dos secciones al momento de analizar acciones de tutela y no como juez especializado en contratación estatal. 


\section{Recomendaciones y propuesta}

No obstante que se concluye que en la actualidad la interpretación con peso de doctrina probable al interior del Consejo de Estado es que la transgresión del principio de planeación da al traste con el contrato estatal al ser causal de anulabilidad del mismo por estar viciado por objeto o causa ilícita, es necesario aclarar que las decisiones que se encontraron que soportan esta posición son de la Subsección C de la Sección Tercera del Consejo de Estado, por lo que convendría que la Sección Tercera en pleno, haciendo uso de las competencias otorgadas por los artículos 270 y 271 del C.P.A.C.A., y dicte una sentencia de unificación por importancia jurídica o necesidad de sentar jurisprudencia en torno al problema objeto de la presente investigación, y de alguna forma entre a zanjar con la fuerza de la sentencia unificadora, la posición en torno a la violación al principio de planeación contractual como causal de nulidad absoluta del contrato estatal.

\section{Referencias bibliográficas}

Alexy, R. (1997). Teoría de la Argumentación Jurídica. Madrid: Editorial Centro de Estudios Políticos y Constitucionales.

Alzate, L.C. (2007). Explicación de la teoría de los principios en Robert Alex. Revista Inciso Facultad de Derecho y Ciencias Políticas Universidad La Gran Colombia (09) 69 - 82.

Alzate, W. (2014). Anuario de Responsabilidad civil y del Estado. Aspectos generales sobre la responsabilidad precontractual a la luz del estatuto general de contratación pública. Medellín: Ediciones Unaula.

Aponte, I. (2014). Las fallas de planeación y su incidencia en el contrato estatal de obra. Revista Digital de Derecho Administrativo (11). Recuperado de https://revistas.uexternado.edu.co/index.php/ Deradm/article/view/3831/4024

Bastidas, R. (2009). El precedente judicial. Bogotá: Ediciones Doctrina y Ley LTDA.

Borowski, M. (2003). La estructura de los derechos fundamentales, Bogotá: Universidad Externado de Colombia.

Brewer-Carías, A.R. (2013). Tratado de derecho administrativo. Madrid: Civitas - Thomson Reuters.

Cassagne, J.C. (2009). Derecho administrativo. Bogotá: Pontificia Universidad Javeriana - Abeledo Perrot.

Cross, R. y Harris, J.W. (2012). El precedente en el derecho inglés. Madrid: Marcial Pons.

Charry, J.M. (1997). Sistema normativo de la constitución de 1991. Bogotá: Temis S.A.

Colombia, Constitución Política.

Colombia, Código Civil.

Colombia, Decreto 1082 de 2015.

Colombia, Leyes 80 de 1993, 489 de 1998, 1150 de 2007 y 1437 de 2011.

Colombia, Consejo de Estado, Sección Tercera, sentencia del 29 de enero de 2004, exp. 10779, M.P. Alier E. Hernández Enríquez. 
Colombia, Consejo de Estado. Sala de lo Contencioso Administrativo. Sección Tercera. Sentencia del 3 de diciembre de 2007. Consejera Ponente Ruth Stella Correa Palacio. Expediente 24715.

Colombia, Consejo de Estado. Sala de lo Contencioso Administrativo. Sección Tercera. Subsección C. Consejero ponente: Jaime OrlandoSantofimio Gamboa. Sentencia del 24 de abril de 2013. Radicación número: 68001231500019980174301 (27315). Actor: Jairo Ospina Cano. Demandado: Área Metropolitana De Bucaramanga. Referencia: Acción de Controversias Contractuales.

Colombia, Consejo De Estado. Sala De Lo Contencioso Administrativo. Sección Tercera. Subsección C. Consejero Ponente: Jaime Orlando Santofimio Gamboa. Sentencia del 13 de junio de 2013. Radicación: 66001233100019990043501 (24.809). Actor: Sociedad Conconcreto S.A. Demandado: Instituto Nacional de Vías -INVIAS- Proceso: Acción Contractual. Asunto: Recurso de Apelación.

Colombia, Consejo de Estado. Sala de lo Contencioso Administrativo. Sección Tercera. Subsección C. Consejero Ponente: Enrique Gil Botero. Sentencia del 24 de julio de 2013. Radicación Número: 05001233100019980083301 (25642). Actor: Andina De Construcciones Ltda. Demandado: Municipio de Ríonegro y Otros. Referencia: Acción de Nulidad y Restablecimiento del Derecho -Contractual-.

Colombia, Consejo de Estado. Sala de lo Contencioso Administrativo. Sección Cuarta. Magistrado ponente: Hugo Fernando Bastidas Bárcenas. Sentencia del 21 de agosto de 2014. Ref.: Expediente N: 11001031500020130191900. Demandante: Constructora Conconcreto S.A. Demandado: Consejo de Estado, Sección Tercera, Subsección C. Sentencia de tutela de primera instancia.

Colombia, Consejo de Estado. Sala de lo Contencioso Administrativo. Sección Quinta. Consejera Ponente: Lucy Jeannette Bermúdez Bermúdez. Sentencia de 27 de noviembre de 2014. Radicación No. 11001031500020130191901. Tutelante: Constructora Conconcreto S.A. Tutelado: Consejo de Estado, Sección Tercera, Subsección "C".

Colombia, Consejo de Estado. Sala de lo Contencioso Administrativo. Sección Tercera. Subsección C. Consejero Ponente: Jaime Orlando Santofimio Gamboa. Sentencia del 27 de enero de 2016. Radicación número: 76001233100020050237100 (49.847). Actor: C.E.S.I. - Centro de Estudios para los Sistemas de Información Demandados: Municipio de Cali. Asunto: Acción de Controversias Contractuales.

Colombia, Consejo de Estado. Sala de lo Contencioso Administrativo. Sección Tercera. Subsección C. Consejero Ponente: Jaime Orlando Santofimio Gamboa. Sentencia del 10 de diciembre de 2015. Radicación número: 73001233100020120001201 (51.489). Actor: Milton Enrique Oviedo Álvarez. Demandados: Municipio de Ibagué - Gestora Urbana. Asunto: Acción Contractual.

Colombia, Consejo de Estado. Sala de lo Contencioso Administrativo. Sección Cuarta. Consejero Ponente: Jorge Octavio Ramírez Ramírez. Sentencia del 3 de agosto de 2016. Radicación: 11001032700020150004400 (21848) Demandantes: Jorge Eliecer Prieto Riveros y otros Demandados: Nación -Ministerio de Hacienda y Crédito Público y Ministerio de Minas y Energía. Referencia: Medio de Control de Nulidad.

Colombia, Consejo de Estado. Sala de lo Contencioso Administrativo. Sección Tercera. Subsección C. Consejero Ponente: Jaime Orlando Santofimio Gamboa. Sentencia del 23 de octubre de 2017. Radicación número: 15001233300020130052601 (55855). Actor: Ingenieros G.F. S.A.S. Demandado: Departamento de Boyacá. Referencia: Medio de Control de Controversias Contractuales. 
Colombia, Corte Constitucional, sentencia C-349 de 1994.

Colombia, Corte Constitucional, sentencia C-329 de 1995.

Colombia, Corte Constitucional, Sentencia C-836 de 2011.

Benavides, J.L. (2004). El contrato estatal. Entre el derecho público y el derecho privado. Bogotá: Editorial Universidad Externado de Colombia.

Dávila Vinueza, L (2003). Régimen jurídico de la contratación estatal. Aproximación crítica a la ley 80 de 1993. Bogotá: Legis.

Deik, C. (2014). Guía de contratación estatal: Deber de Planeación y modalidades de selección, Buenos Aires: AbeledoPerrot.

Dworkin. R. (2000). Los derechos en serio. Barcelona: Ariel.

Escobar Gil, R. (1999). Teoría general de los contratos de la administración pública. Bogotá, Legis.

Estrada, S.I. (2000). La excepción de principialidad. Bogotá: Temis.

Expósito, J.C. (2013). Forma y contenido del contrato estatal. Bogotá: Editorial Universidad Externado de Colombia.

Expósito, J.C. (2004). La configuración del contrato de la administración pública en derecho colombiano y español. Bogotá: Editorial Universidad Externado de Colombia.

López, D.E. (2006). Interpretación constitucional. Bogotá: Escuela Judicial Rodrigo Lara Bonilla.

López, D.E. (2006). El derecho de los jueces. Bogotá: Legis.

González López, E. (2010). El pliego de condiciones en la contratación estatal, la reforma consagrada en la Ley 1150 de 2007 y sus decretos reglamentarios. Bogotá: Editorial Universidad Externado de Colombia.

Palacio, J. A. (2013). La contratación de las entidades estatales. Bogotá: Editorial Librería jurídica Sánchez.

Procuraduría General de la Nación, (2010). Recomendaciones para la elaboración de estudios previosaplicación del principio de planeación en la contratación de las entidades públicas. Bogotá: Publicultural.

Rico P., L.A. (2018). Teoría general y práctica de la contratación estatal. Bogotá: Leyer

Santofimio, J.O. (Ed.). (2010). Contratación estatal. Legislación. Bogotá: Editorial Universidad Externado de Colombia.

Santofimio, J.O. (Ed.). (2009). Contratación estatal. Estudio sobre la reforma al estatuto contractual. Ley 1150 de 2007. Bogotá: Editorial Universidad Externado de Colombia.

Santofimio, J.O. (2010). La fuerza de los precedentes administrativos en el sistema jurídico colombiano. Bogotá: Universidad Externado de Colombia. 
Sierra, H.A. (1998). Concepto y tipos de ley en la constitución colombiana. Bogotá: Universidad Externado de Colombia.

Valencia, H. (1999) Nomoárquica Principalistica Jurídica o de los Principios Generales del Derecho. Bogotá: Temis.

Zagrebelsky, G. (1999). El Derecho Dúctil. Madrid: Trotta. 